CZASOPISMO INŻYNIERII LĄDOWEJ, ŚRODOWISKA I ARCHITEKTURY JOURNAL OF CIVIL ENGINEERING, ENVIRONMENT AND ARCHITECTURE

JCEEA, t. XXXIII, z. 63 (3/16),-wrzesień lipiec 2016, s. 469-476

\author{
Aleksandra ŚCIUBIDLO ${ }^{1}$
}

\title{
INNOWACYJNY SPOSÓB ZAGOSPODAROWANIA POPIOŁÓW LOTNYCH
}

\begin{abstract}
W artykule przedstawiono badania adsorpcji $\mathrm{NO}_{2}$ na zeolitach otrzymanych z popiołów lotnych. Celem badań jest określenie parametrów adsorpcji $\mathrm{NO}_{2}$ na sorbentach stałych i zastosowanie tego procesu w doczyszczaniu spalin $\mathrm{z} \mathrm{NO}_{2}$. Proponowana przez autorów metoda doczyszczani pozwala nie tylko na doczyszczenie spalin przed utylizacją i składowaniem $\mathrm{CO}_{2}$, ale również pozwala na zagospodarowanie odpadów z energetyki z korzyścią dla środowiska poprzez syntezę sorbentów z popiołów lotnych. Na bazie popiołów lotnych zostały otrzymane sorbenty tj. zeolit Na-A i Na-X, które następnie zostały użyte w procesie adsorpcji $\mathrm{NO}_{2}$. Zmiennymi parametrami procesu adsorpcji $\mathrm{NO}_{2}$ była temperatura wygrzewania zeolitów przed procesem adsorpcji oraz stężenie gazu reakcyjnego $\mathrm{NO}_{2}$.
\end{abstract}

Słowa kluczowe: $\mathrm{NO}_{2}$, sorbenty, popiół lotny, zeolit $\mathrm{Na}-\mathrm{A}, \mathrm{Na}-\mathrm{X}$

\section{Wprowadzenie}

Ze względu na porozumienia dotyczące ograniczenia emisji $\mathrm{CO}_{2}$, uważanego za główną przyczynę efektu cieplarnianego, technologia CCS (Carbon Capture and Storage) będzie odgrywała dużą role w ograniczaniu emisji $\mathrm{CO}_{2}$ wykazując największy potencjał redukcji $\mathrm{CO}_{2}$. To właśnie ta technologia wydaje się być najbardziej odpowiednia w krajach, w których głównym paliwem w produkcji energii jest węgiel. Proces wychwytywania i składowania (CCS) składa się z 4 etapów: wychwytywania i sprężania $\mathrm{CO}_{2}$, transportu, wtłaczania i magazynowania. Technologia ta jest obecnie kosztowana a najdroższym etapem jest proces wychwytywania $\mathrm{CO}_{2}$.

Najbardziej rozpowszechnionymi metodami usuwania $\mathrm{CO}_{2}$ jest absorpcyjna metoda aminowa oraz adsorpcja na sorbentach stałych modyfikowanych aminami. W obu tych metodach zachodzi degradacja sorbentów w związku z obecnością $\mathrm{SO}_{\mathrm{x}}$ i $\mathrm{NO}_{\mathrm{x}} \mathrm{w}$ spalinach. Aby zapobiec takiej sytuacji, należy odpowiednio przygotować spaliny przed procesem wychwytywania $\mathrm{CO}_{2}$, tzn. przeprowadzić

\footnotetext{
${ }^{1}$ Aleksandra Ściubidło, Politechnika Częstochowska, Instytut Zaawansowanych Technologii Energetycznych, Wydział Infrastruktury i Środowiska, ul. Dąbrowskiego 73, 42-200 Częstochowa, tel. 343250933, asiubidlo@is.pcz.czest.pl
} 
doczyszczanie spalin. $\mathrm{W}$ przypadku $\mathrm{SO}_{2}$ bezpieczne stężenie nie powinno przekraczać 10ppm w spalinach, a dla tlenków azotu powinno być mniej niż 20 ppm. [1-3] W przypadku spalania $\mathrm{W}$ atmosferze tlenu należy również oczyścić spalin z $\mathrm{NO}_{\mathrm{x}}$ i $\mathrm{SO}_{x}$. Odseparowany $\mathrm{CO}_{2}$ przeznaczony do utylizacji i składowania wymaga również odpowiedniej czystości, jak i przed sprężeniem i transportem rurociągami, tankowcami. Bezpieczne stężenie wynoszą odpowiednie dla $\mathrm{NO}_{\mathrm{x}}<50 \mathrm{ppm}$ i $\mathrm{SO}_{2}<10 \mathrm{ppm}$ ) [4]. W związku z przedstawionymi wymaganiami należy doczyścić spaliny. Niestety zarówno metody pierwotne, jak i wtórne redukcji tlenków azotu, nie pozwalają na osiągnięcie bezpiecznych stężeń tlenków azotu w spalinach, które dalej mogłyby być kierowane do procesu wychwytywania i składowania dwutlenku węgla. Najskuteczniejszą metodą redukcji emisji tlenków azotu jest metoda SCR, pozwalająca na osiągnięcie emisji w granicach $100 \mathrm{mg} / \mathrm{Nm}^{3}$. Niestety wartość ta jest 5-cio krotnie wyższa niż dopuszczalna w przypadku stosowania amin w procesach wychwytywania dwutlenku węgla. W związku z tym autor proponuje innowacyjną metodę doczyszczania spalin z NOx na sorbentach stałych otrzymanych z popiołów lotnych.

Do usuwania $\mathrm{NO}, \mathrm{NO}_{2}, \mathrm{SO}_{2} \mathrm{z}$ gazów stosuje się porowate materiały węglowe, zeolity, materiały mezoporwate, węgiel aktywny, aktywne włókna węglowe.[5] Zarówno zeolity jak i materiały mezoporowate można otrzymać z popiołów lotnych co zostało potwierdzone w badaniach [6-18]. Dotychczas w literaturze nie znaleziono badań dotyczących adsorpcji $\mathrm{NO}_{2}$ na sorbentach stałych tj. zeolity i materiały mezoporowate otrzymanych z popiołów lotnych. $\mathrm{W}$ artykule przedstawiono badania procesu adsorpcji $\mathrm{NO}_{2}$ na sorbentach otrzymanych z popiołów lotnych, na której autor opiera nowatorską metodę doczyszczania spalin $\mathrm{z} \mathrm{NO}_{2} \mathrm{w}$ procesie adsorpcji fizycznej. Autor proponuje alternatywne i przyjazne środowisku sorbenty stałe o wysokiej wydajności energetycznej dla $\mathrm{NO}_{2}$, których zastosowanie eliminuje produkcję dodatkowych odpadów.

\section{Opis procedury badawczej}

W pracy przedstawiono badania adsorpcji $\mathrm{NO}_{2}$ dla 2 różnych materiałów mikroporowatych: zeolitu NaA i NaX otrzymanych z popiołów lotnych i oznaczonych odpowiednio Na-A-FA, Na-X-FA.

Właściwości termiczne zeolitów zbadane zostały z zastosowaniem metody termograwimetrycznej (TG) i analizy kalorymetrii skaningowej różnicowej (DSC) z użyciem analizatora termicznej TGA / DSC1 Mettler Toledo. Próbki sorbentu ogrzewano w tyglu platynowym, pod ciśnieniem atmosferycznym w atmosferze obojętnej $\left(\mathrm{N}_{2}\right)$ z przepływem gazu reakcyjnego $50 \mathrm{ml} / \mathrm{min}$ w zakresie temperatur od 293-1273K ze współczynnikiem szybkości grzania $293 \mathrm{~K} / \mathrm{min}$.

Identyfikację faz krystalicznych oraz faz zeolitowych dokonano metodą rentgenograficzną przy użyciu dyfraktometru proszkowego D8 Advance. Aparat zaopatrzony jest w monochromator Ge (długość promieniowana $\mathrm{CuK}_{\alpha 1}=1,5406 \AA$ ). 
Refleksy rejestrowano przy pomocy detektora paskowego, krzemowego LynxEye. Pomiarów dokonywano przy użyciu kuwet wykonanych z polimetakrylanu metylu. Dyfraktogramy rejestrowano w temp. pokojowej w zakresie $10-70^{\circ}$ kąta $2 \Theta$, z krokiem $0,0499^{\circ}$, przy czasie $1 \mathrm{krok} / \mathrm{sek}$. W trakcie pomiarów próbka była obracana z szybkością 30 obrotów/minutę. Pomiarów dokonano przy prądzie generatora lampy rentgenowskiej o napięciu $35 \mathrm{kV}$ i natężeniu $50 \mathrm{~mA}$.

Badania sorpcji $\mathrm{NO}_{2}$ przeprowadzone zostały również przy użyciu analizatora TGA/SDSC 1 . Na wstępie próbki zostały wygrzane w temperaturze $100^{\circ} \mathrm{C}$ lub $350^{\circ} \mathrm{C}$ (stopień nagrzewania $20 \mathrm{~K} / \mathrm{min}$ ) przez 20 minut w atmosferze obojętnej $\left(\mathrm{N}_{2}\right)$ z przepływem gazu $50 \mathrm{ml} / \mathrm{min}$. Po ochłodzeniu próbki do temperatury $25^{\circ} \mathrm{C}$ realizowany był proces adsorpcji $\mathrm{NO}_{2}$. Do złoża próbki wprowadzony był gaz reakcyjny o stężeniu $110 \mathrm{ppmNO} / \mathrm{N}_{2}$ oraz $50 \mathrm{ppm} \mathrm{NO}_{2} / \mathrm{N}_{2}$ przez okres 60 minut i przepływie $50 \mathrm{ml} / \mathrm{min}$. Proces desorpcji przeprowadzony był $\mathrm{w}$ temperaturze $100^{\circ} \mathrm{C}$ ze stopniem nagrzewania $10 \mathrm{~K} / \mathrm{min}$ w obecności azotu przez 60 minut.

\section{Metodyka i wyniki badań}

Syntezę zeolitów NaA i NaX z popiołu lotnego przeprowadzono zgodnie z procedurą przedstawioną przez autorów [6-9,11-12,14-15]

Sorbenty otrzymane z popiołów lotnych, zeolit Na-A-FA, Na-X-FA zostały poddane analizie termograwimetrycznej. Wyniki przeprowadzonych badań w postaci termogramów, przedstawiono w postaci wykresów obrazujących zależność ubytku masy próbki od temperatury (sygnał TG) oraz jej pierwszej pochodnej (DTG) (rys. 1-2).

Dla zeolitu Na-A-FA (rys.1) jak i zeolitu Na-X-FA (rys.2) ubytek masy rozpoczyna się $w$ temperaturze $50^{\circ} \mathrm{C}$ a kończy w $500^{\circ} \mathrm{C}$. Ubytek masy na krzywych TG i DTG spowodowany jest desorpcją wilgoci i wody zeolitowej. Zawartość wody w zeolicie Na-A-FA wynosi $20 \%$ wag. A dla zeolitu Na-X-FA $17,5 \%$ wag.

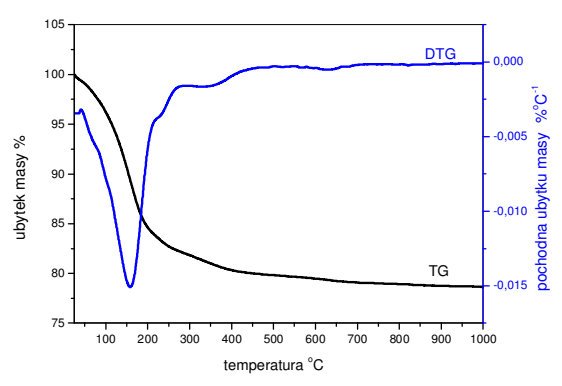

Rys.1. Krzywa TG i DTG zeolitu Na-A-FA

Fig.1. TG and DTG curves of zeolite Na-A-FA

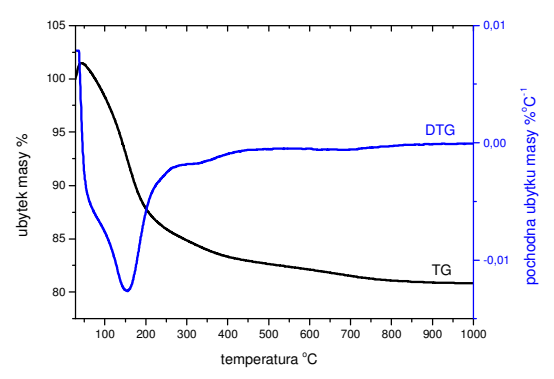

Rys.2. Krzywa TG i DTG zeolitu Na-X-FA

Fig.2. TG and DTG curves of zeolite Na-X-FA 
W celu identyfikacji struktur zeolitowych przeprowadzono badania dyfraktometryczne. Uzyskane widma XRD zeolitów Na-A-FA, Na-X-FA przedstawiono na rys. 3-4. W przypadku próbki nr 1 zaobserwowano obecność zeolitu typu A (A) oraz sodalitu (SO). W przypadku próbki nr 2 zidentyfikowano zeolit typu $\mathrm{X}(\mathrm{X})$ oraz sodalit $(\mathrm{SO})$.

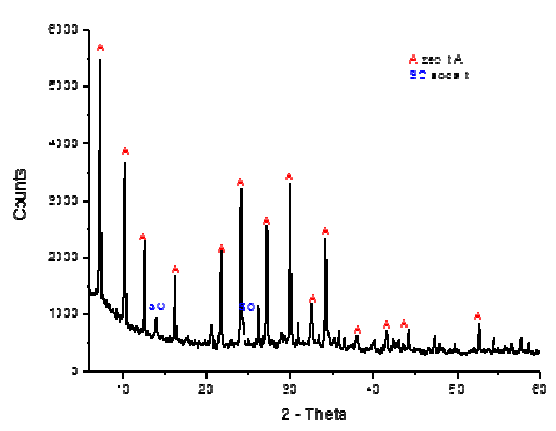

Rys.3. Dyfraktogram XRD zeolitu Na-A-FA

Fig.3. XRD pattern of Na-A-FA

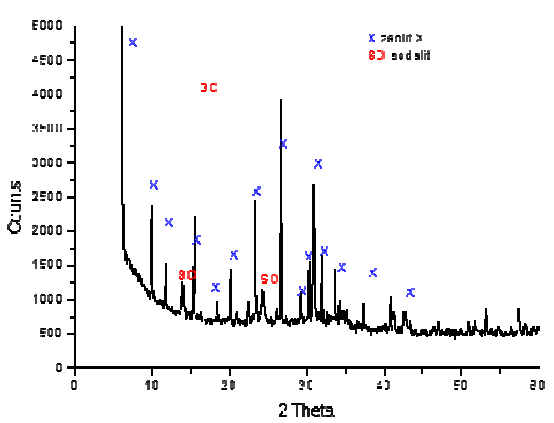

Rys.4. Dyfraktogram XRD zeolitu Na-X-FA

Fig.4. XRD pattern of Na-X-FA

W drugim etapie badań przeprowadzono proces adsorpcji na otrzymanych zeolitach z popiołów lotnych. Przed procesem adsorpcji próbki wygrzewano $\mathrm{w}$ temperaturze $100^{\circ} \mathrm{C}$ przez 20 minut w przepływie azotu ze stopniem nagrzewania $20 \mathrm{~K} / \mathrm{min}$. Proces adsorpcji przeprowadzono przez 60 minut w temperaturze $25^{\circ} \mathrm{C}$, o stężeniu gazu reakcyjnego $110 \mathrm{ppmNO}_{2} / \mathrm{N}_{2}$ i przepływie gazu $50 \mathrm{ml} / \mathrm{min}$. Pojemność sorpcyjną sorbentów wyrażono w $\mathrm{mg} \mathrm{NO} / \mathrm{g}$ adsorbentu. $\mathrm{Na}$ rys.5 przedstawiono wyniki adsorpcji $\mathrm{NO}_{2}$ na zeolicie Na-A-FA otrzymanym z popiołu lotnego. Pojemność sorpcyjna tego sorbentu wyniosła 4,59 $\mathrm{mg} \mathrm{NO}_{2} \mathrm{~g}^{-1}$ sorbentu.

W przypadku zeolitu Na-X-FA (rys.6) pojemność sorpcyjna wyniosła $4,40 \mathrm{mg} \mathrm{NO}_{2} \mathrm{~g}^{-1}$ sorbent. Zeolit Na-A-FA charakteryzował się nieznacznie wyższą pojemnością sorpcyjną $\mathrm{NO}_{2}$ niż zeolit NA-X-FA.
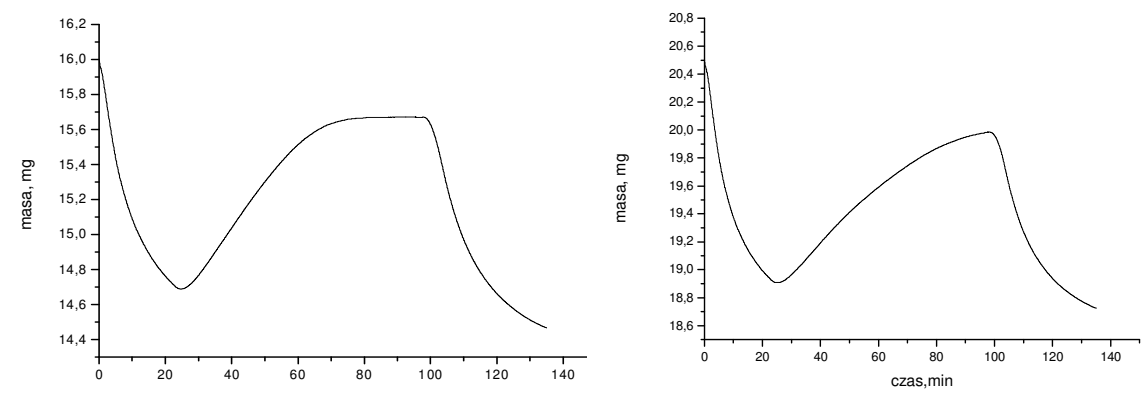

Rys.5. Krzywa sorpcji $\mathrm{NO}_{2}$ na zeolicie Na-A-FA Rys.6. Krzywa sorpcji $\mathrm{NO}_{2}$ na zeolicie Na-X-FA

Fig.5. Adsorption curve of NO2 on zeolite Na-A-FAFig.6. Adsorption curve of NO2 on zeolite Na-A-FA 
W badaniach określono wpływ temperatury wygrzewania próbek przed procesem adsorpcji, na pojemność sorpcyjną sorbentów względem $\mathrm{NO}_{2}$. W tym celu temperatura wygrzewania sorbentów została podniesiona z $100^{\circ} \mathrm{C}$ do $350^{\circ} \mathrm{C}$. Pozostałe parametry nie uległy zmianie. Na rys. 7 przedstawiono wynik adsorpcji $\mathrm{NO}_{2}$ na zeolicie Na-A-FA. Pojemność sorpcyjna tego sorbentu wyniosła $6,77 \mathrm{mg} \mathrm{NO}_{2} \mathrm{~g}^{-1}$ sorbentu. W przypadku zeolitu Na-X-FA (rys.8) pojemność sorpcyjna wyniosła $6,09 \mathrm{mg} \mathrm{NO}_{2} \mathrm{~g}^{-1}$ sorbent. Zeolit Na-A-FA charakteryzował się wyższą pojemnością sorpcyjną $\mathrm{NO}_{2}$ w porównaniu do zeolitu NA-X-FA.

W badaniach określono również wpływ stężenia gazu reaktywnego podczas procesu adsorpcji na pojemność sorpcyjną próbek. W tym celu użyto gazu reaktywnego o stężeniu $50 \mathrm{ppmNO}_{2} / \mathrm{N}_{2}$. Pozostałe parametry nie uległy zmianie.
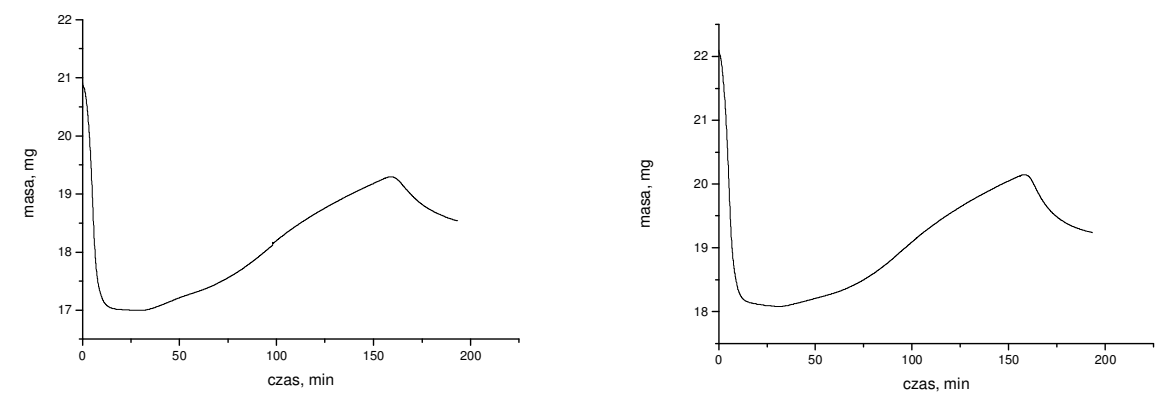

Rys.7. Krzywa sorpcji $\mathrm{NO}_{2}$ na zeolicie Na-A-FA Rys.8. Krzywa sorpcji $\mathrm{NO}_{2}$ na zeolicie Na-X-FA

Fig.7. Adsorption curve of NO2 on zeolite Na-A-FAFig.8. Adsorption curve of NO2 on zeolite Na-A-FA

Na rys. 9 przedstawiono krzywą adsorpcji $\mathrm{NO}_{2}$ na zeolicie Na-A-FA, dla którego pojemność sorpcyjna wyniosła $0,039 \mathrm{mg} \mathrm{NO}_{2} \mathrm{~g}^{-1}$ sorbentu. Zeolit Na-AFA (rys.10) charakteryzował się wyższą pojemnością sorpcyjną $\mathrm{NO}_{2}$ równą $7,77 \mathrm{mg} \mathrm{NO}_{2} \mathrm{~g}^{-1}$ sorbentu w porównaniu do zeolitu NA-X-FA.
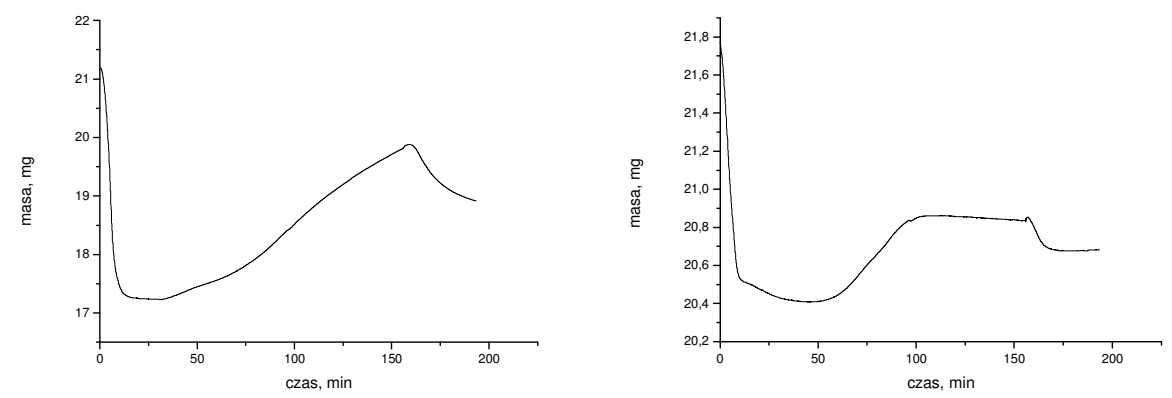

Rys.9. Krzywa sorpcji $\mathrm{NO}_{2}$ na zeolicie Na-A-FA Rys.10. Krzywa sorpcji $\mathrm{NO}_{2}$ na zeolicie Na-X-FA

Fig.9. Adsorption curve of $\mathrm{NO}_{2}$ on zeolite Na-A-FA Fig.10. Adsorption curve of $\mathrm{NO}_{2}$ on zeolite Na-A-FA 


\section{Analiza wyników}

W tabeli 1 porównano wyniki przeprowadzonych badań adsorpcji dla zeolitów otrzymanych z popiołów lotnych Na-A-FA i Na-X-FA przy różnych parametrach procesu adsorpcji. Jak widać z badań we wszystkich przypadkach wyższą pojemnością sorpcyjną charakteryzował się zeolit Na-A-FA. Podniesienie temperatury wygrzewania zeolitów z $100^{\circ} \mathrm{C}$ do temperatury $350^{\circ} \mathrm{C}$ wpłynęło na wzrost pojemności sorpcyjnej obu zeolitów. W przypadku zeolitu Na-A-FA pojemność sorpcyjna wzrosła o $2,18 \mathrm{mg} \mathrm{NO}_{2} \mathrm{~g}^{-1}$ sorbentu a dla zeolitu Na-X-FA wzrost wyniósł $1,69 \mathrm{mg} \mathrm{NO} \mathrm{g}^{-1}$ sorbentu. Najwyższą pojemność sorpcyjną względem $\mathrm{NO}_{2}$ charakteryzował się zeolit Na-A-FA przy stężeniu gazu reakcyjnego o stężeniu 50ppm $\mathrm{NO}_{2} / \mathrm{N}_{2}$.

Tabela 1. Zestawienie wyników pojemności sorpcyjnej sorbentów

Table 1. The results of sorption capacity of sorbents

\begin{tabular}{|c|c|c|c|}
\hline Nazwa próbki & $\mathrm{C}_{\mathrm{NO} 2 / \mathrm{N} 2}$ & $\mathrm{~T}_{\text {wyg. }}=100^{\circ} \mathrm{C}$ & $\mathrm{T}_{\text {wyg. }}=350^{\circ} \mathrm{C}$ \\
\hline Na-A-FA & $50 \mathrm{ppm}$ & - & 7,77 \\
\hline Na-X-FA & $50 \mathrm{ppm}$ & - & 0,039 \\
\hline Na-A-FA & $110 \mathrm{ppm}$ & 4,59 & 6,77 \\
\hline Na-X-FA & $110 \mathrm{ppm}$ & 4,40 & 6,09 \\
\hline
\end{tabular}

\section{Wnioski}

Celem prowadzonych badań było określenie parametrów procesu adsorpcji $\mathrm{NO}_{2}$ na sorbentach stałych otrzymanych z popiołów lotnych a następnie wykorzystanie adsorpcji $\mathrm{NO}_{2} \mathrm{w}$ procesie doczyszczania splin z $\mathrm{NOx}$ i $\mathrm{SO}_{2}$. Metoda ta pozwala na doczyszczenie spalin przed utylizacją i składowaniem $\mathrm{CO}_{2}$, jak również pozwala na zagospodarowanie odpadów z energetyki z korzyścią dla środowiska poprzez syntezę sorbentów na bazie popiołów lotnych. Każda z próbek charakteryzowała się zmienną pojemnością sorpcyjną $\mathrm{NO}_{2}$. Najwyższą pojemnością sorpcyjną wynoszącą 7,77 $\mathrm{mg} \mathrm{NO}_{2} \mathrm{~g}^{-1}$ sorbentu charakteryzował się zeolit Na-A-FA a najmniejszą zeolit Na-X-FA równą $0,039 \mathrm{mg} \mathrm{NO}_{2} \mathrm{~g}^{-1}$ sorbentu Przeprowadzone badania pozwoliły na określenie wpływu temperatury wygrzewania zeolitów na ich pojemność sorpcyjną $\mathrm{NO}_{2}$, która wzrasta wraz ze wzrostem temperatury wygrzewania. Zauważono również wzrost pojemności sorpcyjnej wraz ze wzrostem stężenia gazu reakcyjnego $\left(\mathrm{NO}_{2}\right)$. Przedstawione badania potwierdziły, iż zeolit NA-A-FA charakteryzuje się lepszymi właściwościami sorpcyjnymi względem $\mathrm{NO}_{2}$ niż zeolit NA-X-FA. 


\section{Literatura}

[1] IEA GHG, CO2 capture ready plants, IEA GHG, Report 2007/4, 2007.

[2] VIORICA CEBRUCEAN, IOANA IONEL, CO2 Capture from Flue Gas with Monoethanolamine, REV. CHIM. (Bucharest), 63, No. 7, 2012, 678-681.

[3] X.Xu,C.Song,R.Wincek,J.M.Andresen,B.G.Miller,.W.Scaroni, 2003. Separation of $\mathrm{CO} 2$ from power plant flue gas using a novel CO2 "molecular basket" adsorbent. In: Prepr. Am. Chem. Soc. Div. Fuel Chem. 48, pp. 162-163.

[4] G. Pipitone and O. Bolland, Environ. Prog. Sustain. Energy, 2008, 28, 20.

[5] Fateme Rezaei, Ali A. Rownaghi, Saman Monjezi, Ryan P. Lively, and Christopher W. Jones, $\mathrm{SO}_{x} / \mathrm{NO}_{x}$ Removal from Flue Gas Streams by Solid Adsorbents: A Review of Current Challenges and Future Directions, Energy Fuels, 2015, 29 (9), pp 54675486.

[6] A.Sciubidło,W.Nowak, Novel sorbents for flue gas purificatio, Journal of Power Technologies 92,(2),(2012) 115-126.

[7] H.L. Chang, C.M. Chun, I. A. Aksay, W.H.Shih, Conversion of Fly Ash into Mesoporous Aluminosilicate, Ind. Eng. Chem. Res., 1999, 38 (3), pp. 973-977.

[8] P. Kumar, N. Mal, Y. Oumi, K. Yamanaa, T. Sano, Mesoporous materials prepared using coal fly ash as the silicon and aluminium source, J. Mater. Chem., 2001, 11, pp. 3285-3290.

[9] I.Majchrzak-Kucęba, A. Ściubidło, W. Nowak, 26th Annual International Pittsburgh Coal Conference, Studies on the properties of mesoporous materials derived from polish fly ashes, Materiały Konferencyjne, Pittsburgh, 20-23 September 2009.

[10] I.Majchrzak-Kucęba, A. Ściubidło, W. Nowak, Characterization of Zeolites from Polish Fly Ashes. 26th Annual International Pittsburgh Coal Conference, Studies on the properties of mesoporous materials derived from polish fly ashes, Materiały Konferencyjne, Pittsburgh, 20-23 September 2009.

[11] A. Ściubidło, W. Nowak Doczyszczanie spalin z tlenków azotu przy użyciu sorbentów z popiołów lotnych, Polska Inżynieria Środowiska Prace. Pod red. Marzenna Dudzińska, Artur Pawłowski. T.1, s.299-305, Lublin, 2012.

[12] I.Majchrzak-Kucęba, A. Ściubidło, W. Nowak, Utilization of Fly Ash from Polish Power Plants and Thermal-Electric Power Stations Through the Modification of Ash Into Mesoporous Materials. International Conference EuroCoalAsh. Monograph. Ed. Tomasz Szczygielski.Warsaw, 2008, s.181-197.

[13] I.Majchrzak-Kucęba, A. Ściubidło, W. Nowak Synteza zeolitu Na-X z popiołów lotnych. Sorbenty z popiołu dla energetyki. Red. nauk. Wojciech Nowak, Józef Pacyna, Izabela Majchrzak-Kucęba. s. 39-57, Częstochowa, 2010.

[14] I.Majchrzak-Kucęba, A. Ściubidło, W. Nowak Fly Ash-Based Sorbents for PostCombustion Capture CO2. International Conference EuroCoalAsh. Monograph. Ed. Tomasz Szczygielski.Warsaw, 2008, s. 101-110.

[15] I.Majchrzak-Kucęba, A. Ściubidło, W. Nowak Mezoporowate materiały z popiołów lotnych do separacji dwutlenku węgla ze spalin, Popioły z energetyki. Monografia. Red. Tomasz Szczygielski, s. 85-94 ,Szczecin, 2007. 
[16] D.Sztekler, I.Majchrzak-Kucęba, W.Nowak, ; Analysis of the chemical composition of coal fly ash for synthesis zeolite $\mathrm{Na}-\mathrm{A}$; PAN, vol. 58, Tom1., str. 313-320, 2009.; (2009).

[17] A.Ściubidło, I.Majchrzak-Kucęba,W. Nowak, Influence of the chemical composition of the fly ashes on the efficiency of the synthesis zeolites Na-X, PAN; vol.59; (2009); str. 225-237.

[18] W.Nowak, A.Ściubidło, Synteza mezoporowatego sita MCM-41 z popiołów lotnych do usuwania tlenków azotu, XVI Międzynarodowa Konferencja Popioły z energetyki, 21-24 październik 2009, Zakopane, str.371-383.

\section{AN INNOVATIVE METHOD FOR UTILIZATION OF FLY ASH}

\section{S u m m a r y}

The article presents studies the adsorption of $\mathrm{NO}_{2}$ on zeolites obtained from fly ash. The aim of the study is to determine the parameters of the adsorption of $\mathrm{NO}_{2}$ on solid sorbents. The proposed method allows for purifying of the exhaust before capture and storage of $\mathrm{CO}_{2}$. It allows utilization of waste from power plants through the synthesis of sorbents from fly ash. Obtained zeolite $\mathrm{Na}-\mathrm{A}$ and $\mathrm{Na}-\mathrm{X}$ are used in adsorption of $\mathrm{NO} 2$. Varying parameters adsorption of $\mathrm{NO}_{2}$ was the heating temperature of the zeolite before the adsorption process and the concentration of the reaction gas $\mathrm{NO}_{2}$.

Keywords: $\mathrm{NO}_{2}$, sorbents, fly ash, $\mathrm{Na}-\mathrm{A}, \mathrm{Na}-\mathrm{X}$

DOI:10.7862/rb.2016.230

Przestano do redakcji: $13.06 .2016 \mathrm{r}$.

Przyjęto do druku: $30.11 .2016 r$. 